\title{
Aumentando a Motivação do Estudante com um Sistema de Exercícios Colaborativo e Gamificado
}

\author{
Claudia Pimentel $^{1}$, Isabela Gasparini ${ }^{1,2,3}$ \\ ${ }^{1}$ Departemento de Ciência da Computação, ${ }^{2} \mathrm{PPGECMT},{ }^{3} \mathrm{PPGCA}$ \\ Universidade do Estado de Santa Catarina (UDESC) - Joinville, SC - Brasil \\ claupimentel98@gmail.com, isabela.gaspariniludesc.br
}

\begin{abstract}
Virtual Learning Environments have high dropout rates in their courses. This fact may be related to the student's lack of motivation and interest. To solve this problem a collaborative and gamified exercises system is proposed, where the student can create questions and others can answer and evaluate them. It is hoped that with this tool the learning process will become more engaging, motivating, active and effective.
\end{abstract}

Resumo. Ambientes Virtuais de Aprendizagem (AVAs) apresentam altas taxas de evasão em seus cursos. Este fato pode estar relacionado com a falta de motivação e interesse do estudante. Para a resolução desse problema, propõese um sistema de exercícios colaborativo e gamificado, onde o aluno possa criar questões e que os demais estudantes possam respondê-las e avaliá-las. Espera-se que com esta ferramenta o processo de aprendizagem se torne mais envolvente, motivador, ativo e efetivo.

\section{Introdução}

A educação é uma área em que novas técnicas podem ser aplicadas para que os estudantes, que cada vez têm mais contato com tecnologia, se motivem e aumentem seu interesse no processo de ensino e aprendizagem, especialmente em processos tradicionais como a sala de aula [Fardo 2013]. A motivação trata-se dos estímulos que uma pessoa recebe para alcançar seus objetivos [Ogawa 2017]. E a falta dela ocorre também em Ambientes Virtuais de Aprendizagem (AVAs), sendo a principal causa de desistência nos mesmos [Visser et al. 2002]. Logo, busca-se usar a gamificação em AVAs para promover ao estudante um aprendizado mais eficiente e envolvente [Muntean 2011].

A gamificação consiste em utilizar elementos de jogos, como o pensamento, a estética e a mecânica, para envolver e motivar pessoas, promover aprendizagem e resolver problemas [Kapp 2012]. Ela não se trata de uma técnica única que resolverá todos os problemas, mas que é muito útil para ajudar usuários a alcançar objetivos propostos [Alves 2014].

Para o processo de aprendizagem se tornar mais ativo e efetivo utiliza-se o conceito de aprendizagem colaborativa, que se trata de encorajar o aluno a participar mais, trabalhando com outros alunos direta ou indiretamente [Torres, Alcântara e Irala 2004]. Sabendo dos benefícios da gamificação e da aprendizagem colaborativa, este 
VII Congresso Brasileiro de Informática na Educação (CBIE 2018)

Anais do XXIX Simpósio Brasileiro de Informática na Educação (SBIE 2018)

artigo tem como objetivo propor a implementação de um sistema de exercícios gamificado e colaborativo para o ambiente AdaptWeb ${ }^{\circledR}$ (Ambiente de Ensino e Aprendizagem Adaptativo na $\mathrm{Web}$ ), com intuito de promover maior participação, colaboração e engajamento aos estudantes, de forma que eles possam criar suas próprias questões para as disciplinas que estão matriculados e com isso compartilhar, aprimorar e obter novos conhecimentos.

\section{Proposta}

O projeto apresentado neste artigo será implementado no AdaptWeb ${ }^{\circledR}$, um sistema adaptativo de educação a distância que busca se adaptar de acordo com o perfil do estudante. Existem duas maneiras de acessar o ambiente, a de professor, que pode criar e gerenciar disciplinas e cursos e a de estudante, que pode acessar o ambiente de aula e outras funções relacionadas as disciplinas que está matriculado. Este trabalho atua tanto no ambiente do estudante quanto no ambiente do professor.

No ambiente do estudante, atualmente restrito em assistir as aulas oferecidas pelo professor (materiais, conceitos, exemplos, exercícios), ele poderá atuar de forma ativa, criando seus próprios exercícios, que poderão ser respondidos e avaliados por outros estudantes e o professor da disciplina. Como premiação por sua participação, o estudante ganhará pontos de gamificação, emblemas e poderá participar de rankings com os demais colegas de sua turma. Já o ambiente do professor, poderá fazer o acompanhamento, avalição e gerenciamento das questões criadas pelos estudantes.

A gamificação aplicada para o sistema de exercícios será baseada no trabalho de Klock (2017), que propõe o Framework 5W2H, para auxiliar no desenvolvimento e avaliação da gamificação. O Framework trata sete dimensões para a aplicação em sistemas educacionais, que são: “Quem?”, que identifica o usuário e explora seu perfil, "O quê?", que identifica que comportamento deve ser estimulado ou não, "Por quê?", identifica quais estímulos devem ser gerados aos usuários, “Quando?”, identifica quais momentos devem haver estímulos, "Como?", identifica quais elementos devem ser utilizados, "Onde?", identifica o que deve ser alterado no sistema para conseguir estimular os usuários, e "Quanto?", avalia se a implementação da gamificação estimulou os usuários do sistema.

O processo de design e concepção do sistema de exercícios colaborativo e gamificado está sendo apoiado por workshops com alunos e professores, brainstorming com um grupo de pesquisa multidisciplinar com participação de aproximadamente trinta pessoas e prototipação de baixa fidelidade para comunicação e análise das ideias geradas. As etapas são iterativas e em conjunto com os usuários. A seguir serão apresentadas as visões dos usuários (estudante e professor) para o novo sistema de exercícios.

\subsection{Visão do Estudante}

O estudante poderá criar questões vinculadas a tópicos da disciplina que está matriculado, essas questões podem ser dos tipos assinalar a correta, verdadeiro ou falso ou múltipla escolha, como pode ser visualizado na Figura 1.a). Essa decisão foi tomada para que o estudante colabore com os outros, compartilhando conhecimento, seja mais ativo no seu processo de aprendizagem, pesquisando os temas mais afundo para elaborar 
VII Congresso Brasileiro de Informática na Educação (CBIE 2018)

Anais do XXIX Simpósio Brasileiro de Informática na Educação (SBIE 2018)

as questões e como consequência se sinta mais motivado a estudar e envolvido com a disciplina.

Após a questão ser criada o estudante ganhará pontos no sistema de gamificação já existente, para que ele tenha cada vez mais vontade de participar do ambiente e então a questão será disponibilizada automaticamente aos demais estudantes.

As questões criadas pelos estudantes serão sinalizadas de forma diferenciada no ambiente, como pode ser visualizado na Figura 1.b), sem indicar a autoria, para que a avaliação dos exercícios criados entre os estudantes não leve em consideração questões pessoais. Desta forma, quando um estudante estiver na seção de exercícios, ele saberá se o exercício foi proposto pelo professor ou pela sua turma.

Após um estudante responder uma questão criada por outro estudante, ele poderá avaliar a questão com "gostei" ou "não gostei" como pode ser visto na Figura 2.a). Poderá também reportar erro caso a questão apresente alguma inconsistência, assim como mostra a Figura 2.b). Quando uma questão for reportada ela só será exibida aos estudantes novamente, após a verificação do professor. Essa estratégia foi tomada para não sobrecarregar o professor que não precisará verificar todas as questões criadas pelos estudantes. Quanto ao sistema de gamificação, o estudante poderá visualizar os rankings que levarão em conta apenas as questões criadas pela sua turma, a quantidade de vezes que suas questões foram respondidas, o número de avaliações positivas e negativas com "gostei" ou "não gostei", se foram reportadas e a decisão do professor quanto a isso, para que ele tenha um feedback do seu desempenho elaborando as questões e também para estimular o aumento de seu engajamento na disciplina, principalmente na parte colaborativa.

\subsection{Visão do Professor}

Para auxiliar o gerenciamento das questões criadas pelos estudantes em cada disciplina, o professor terá acesso às questões e informações como quem criou, data da criação, tópico da disciplina que a questão pertence, quantas respostas ela obteve, etc. Para que ele possa acompanhar a evolução da turma, saber os tópicos mais populares da disciplina e o nível de participação dos estudantes. Quando uma questão é reportada o professor será notificado e poderá analisar a questão e suas alternativas, tendo a opção de editar a questão, caso a inconsistência seja pequena, apagá-la, se achar necessário ou esclarecer ao estudante que reportou o porquê a questão está correta, como uma forma de feedback. 
VII Congresso Brasileiro de Informática na Educação (CBIE 2018)

Anais do XXIX Simpósio Brasileiro de Informática na Educação (SBIE 2018)

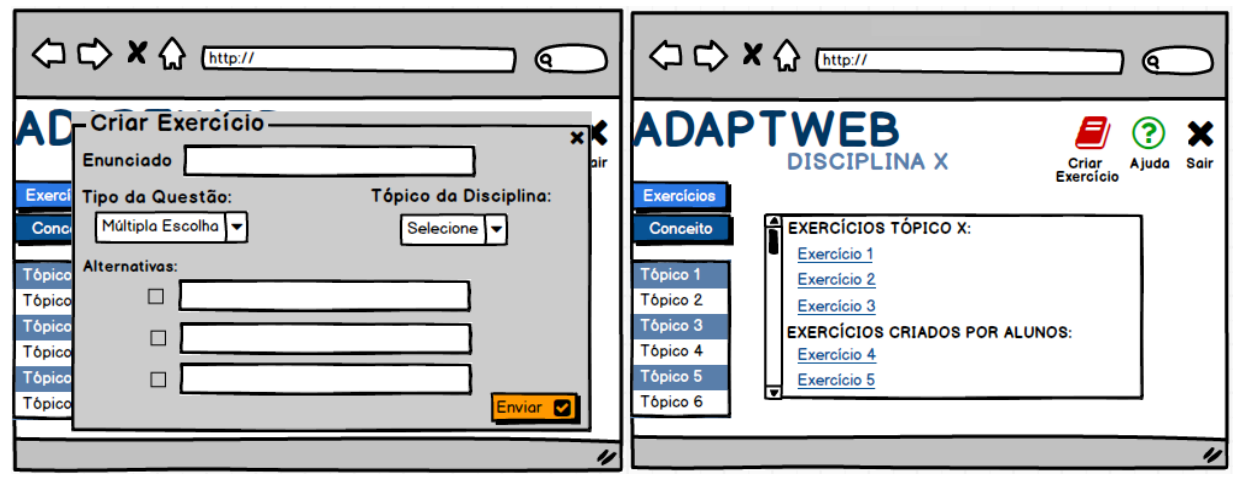

Figura 1. a) Interface para criar um exercício (esquerda); b) visualização de exercícios (direita)
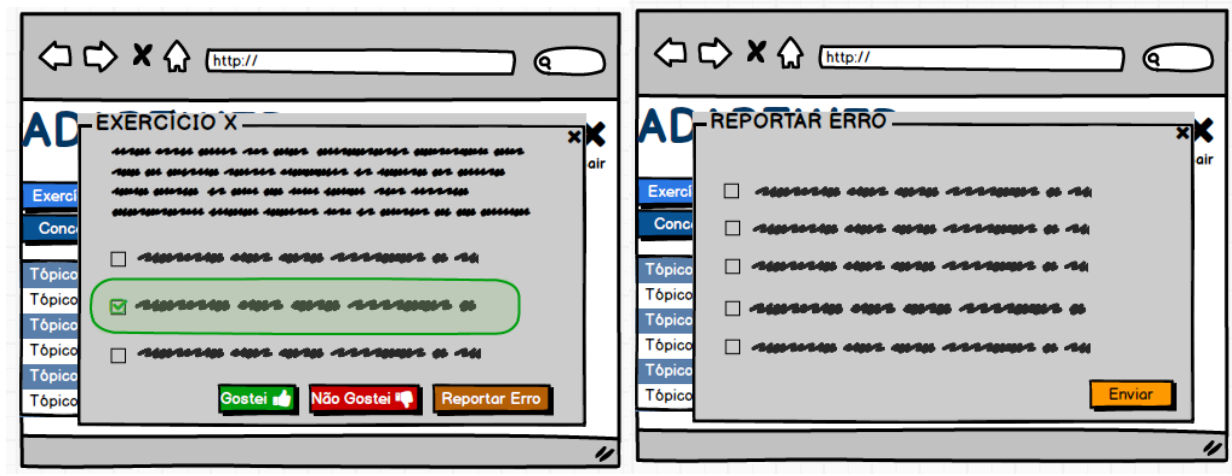

Figura 2. a) Interface para avaliar um exercício criado por outro estudante (esquerda); b) reportar erro ou inconsistência na questão(direita)

\section{Considerações Finais}

Atualmente esta pesquisa encontra-se em andamento, por este motivo algumas decisões podem ser alteradas futuramente como o fato de as questões dos estudantes não passarem por nenhum filtro antes de serem publicadas, o sistema não oferecer a possibilidade de criação de questões mais complexas, que tenham respostas dissertativas por exemplo e não haver verificação de plágio no sistema. O projeto apresentado de um sistema de exercícios colaborativo e gamificado já está em implementação e como trabalhos futuros, destaca-se a finalização dos ambientes do professor e estudante, testes funcionais e experimentos reais com estudantes e professores que utilizam o ambiente AdaptWeb, além da análise dos resultados do experimento. Como resultado, espera-se que os estudantes se sintam motivados a participar ativamente do ambiente, criando, respondendo e avaliando questões e como consequência, tenham um aprendizado mais efetivo e agradável.

\section{Agradecimentos}

Agradecemos ao apoio financeiro da FAPESC, Edital chamada pública FAPESC/CNPQ $\mathrm{N}^{\mathrm{o}}$ 06/2016 apoio a infraestrutura de CTI para jovens pesquisadores, projeto T.O. $\mathrm{N}^{\mathrm{o}}$ : 2017TR1755 - Ambientes Inteligentes Educacionais com Integração de Técnicas Learning Analytics e Gamificação. O presente trabalho foi realizado com apoio da 
VII Congresso Brasileiro de Informática na Educação (CBIE 2018)

Anais do XXIX Simpósio Brasileiro de Informática na Educação (SBIE 2018)

Coordenação de Aperfeiçoamento de Pessoal de Nível Superior - Brasil (CAPES) Código de Financiamento 001.

\section{Referências}

Alves, F.P. (2014) "Gamification como criar experiências de aprendizagem engajadoras um guia completo: do conceito a pratica”. São Paulo: DVS editora.

Fardo, M. F. (2013) “A Gamificação Aplicada em Ambientes de Aprendizagem”. Renote Novas Tecnologias na Educação, v. 11, n. 1.

Kapp, Karl M. (2012) "The gamification of learning and instruction: game-based methods and strategies for training and education". John Wiley \& Sons.

Klock, A. C. T. (2017) "Análise da Influência da Gamificação na Interação, na ComunicaçãoenoDesempenhodosEstudantesemumSistemadeHipermídiaAdaptativo Educacional". Dissertação (Mestrado em Computação Aplicada - Área: Engenharia de Software). Universidade do Estado de Santa Catarina.

Muntean, C. I. (2011) "Raising engagement in e-learning through gamification". The 6th International Conference on Virtual Learning ICVL.

Ogawa, A; Klock, A. C. T; Gasparini, I. (2017) "Integrando Técnicas de Learning Analytics no processo de Gamificação em um Ambiente Virtual de Aprendizagem", SBIE - Simpósio Brasileiro de Informática na Educação.

Visser, L.; Plomp, T.; Amirault, R.; Kuiper, W. (2002) "Motivating students at a distance: The case of an international audience". Journal of Educational Technology Research and Development.

Torres, P. L.; Alcântara, P. R.; Irala, E. A. F. (2004) "Grupos de consenso: uma proposta de aprendizagem colaborativa para o processo de Ensino-aprendizagem." Revista Diálogo Educacional, v.4, n.13. 